\title{
Metagenomics of wheat rhizosphere for abiotic stress management
}

Om Parkash Ahlawat*, Ratan Tiwari and Gyanendra Pratap Singh

ICAR-Indian Institute of Wheat and Barley Research, Karnal, India

\section{Article history}

Received: 11 May, 2018

Revised : 13 June, 2018

Accepted: 09 July, 2018

\section{Citation}

Ahlawat OP, R Tiwari and GP Singh. 2018. Metagenomics of wheat rhizosphere for abiotic stress managment. Wheat and Barley Research 10(2):64-77. doi.org/10.25174/2249$4065 / 2018 / 79291$

\section{*Corresponding author}

Email: om.ahlawat@icar.gov.in/ ahlawat22op@gmail.com

\section{Introduction}

In line with the name given to the microorganisms inhabiting the human body, the plant-associated microorganisms are referred as the plant microbiome or second or extended genome. So the plants are not the simple organism as we think but they are superorganisms that depend upon to a certain extent on their microbiome for performing specific functions and features. The plant microbiome comprises different classes of microorganisms that includes viruses, bacteria, archaea, fungi and oomycetes. The number of microorganisms, which colonizes plants, can reach in cell densities much higher than the number of cell in a plant (Fig. 1). Similarly, the numbers of microbial genes present in plant rhizosphere are higher than the number of genes present in a plant (Fig. 1). The members of the rhizosphere microbiome exert significant effect on germination of seeds, vigor of the seedlings, growth and further development of plants, incidence of diseases and overall productivity by way of supporting nutrient uptake, exerting tolerance against biotic and abiotic components of the environment and regulation of the plant immune system (Berendsenet al., 2012; Bakker et al., 2013; Mendes et al., 2013; Turner et al., 2013; Berg et al., 2014; Lakshmanan et al., 2014; Perez-Jaramillo et al., 2016). There are reports available where it has been said that in only few cases, the natural selection in plants helps in acquiring the resistance against belowground pathogens and the plant to a certain extent depends upon the rhizospheric microorganisms for its defense against pathogens (Cook et al., 1995). There are also reports available where the specific microbial consortia present in disease suppressive soils protect the plant from infection by the soil borne pathogens (Mendes et al., 2011).

In return to the support received from the rhizosphere microorganisms, the plants supply the carbon sources to feed the rhizospheric microorganisms and consequently determine their composition (Nelson, 2004; Berendsenet $a l ., 2012)$.The plant rhizodeposits are comprised of root 
exudates, border cells and mucilage, and all these have role in determining the microbial activity and the diversity in the rhizosphere. All facets of interactions between plants and the rhizospheric microorganisms involving root exudates, process of root exudates mediated rhizospheric interactions, ways of affecting the microbial community through root exudates, significance of microbial community in such interactions and consequently the benefits plant receive through these interactions have been reviewed and depicted in Fig. 2 (Huang et al., 2014). The prevailing biotic and abiotic factors also influence the root exudation process and root exudates composition, which further determine the microbial composition of the rhizosphere (Lakshmanan et al., 2012). Further in this study, the role of microbe-associated molecular patterns (MAMPs) of Arabidopsis leaves in promotion of colonization by Bacillus subtilis strain FB17 via expression of root malic acid (MA) transporter (ALMT1) has also been discussed.

It can be inferred that plants may regulate the rhizospheric microbiome to their favour by promoting the growth of microorganisms which are beneficial to their growth and health (Cook et al., 1995). However, there are counter views also, where it has been said that root exudates are nothing but passively released overflow/waste material of the plant (Hartmann et al., 2009; Jones et al., 2009; Dennis et al., 2010). Till now most of the studies on interactions between plants and microorganisms are restricted to leaf pathogens, symbiotic relationship between roots and rhizobia and the mycorrhizal fungi. However, a majority of the rhizospheric microbiome has remained untouched and their role in different plant functions like growth, health and tolerance against abiotic and biotic stresses is still at infancy stage. Hence, it is imperative to decipher the plant microbiome in order to identify the microorganisms or the genes for their exploitation in improving plant growth, extending tolerance to biotic and abiotic stresses, and plant health. In this context Mendes et al. (2013) has rightly stressed that it is essential to understand the processes, which determine and stimulate the compositional changes in the rhizosphere microbiome, to safeguard plant productivity.

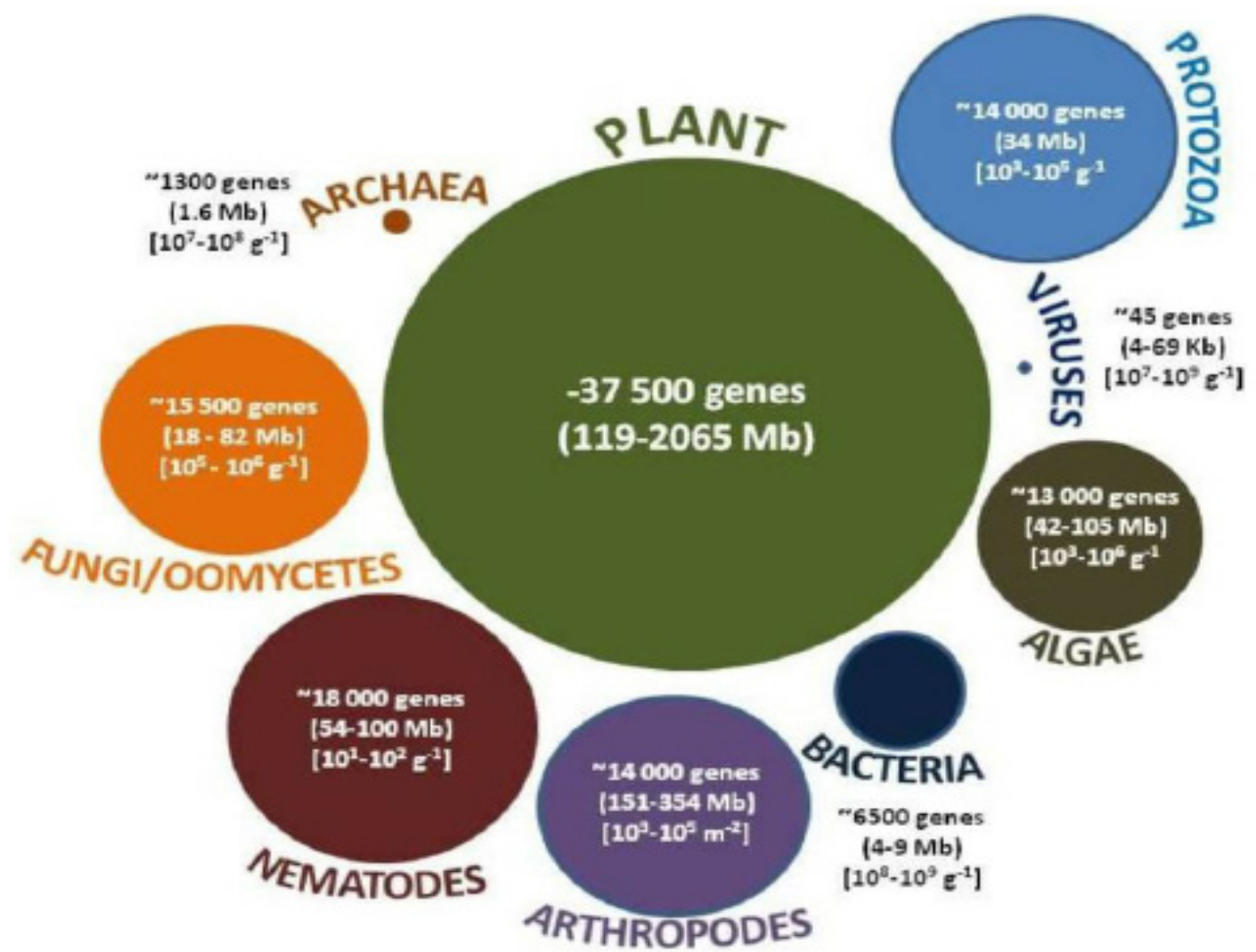

Fig. 1. Pictorial depiction of microorganisms present in the plant rhizosphere. The size of circles', except for viruses, represent the average numbers of genes in the representative species; the genome size or size range is depicted within parentheses. The approximate numbers of different microorganisms for their abundance are indicated within square brackets (Brady, 1974; Alexander, 1977; Lynch, 1988; Meeting, 1992; Buee et al., 2009; Mendes et al., 2013). 


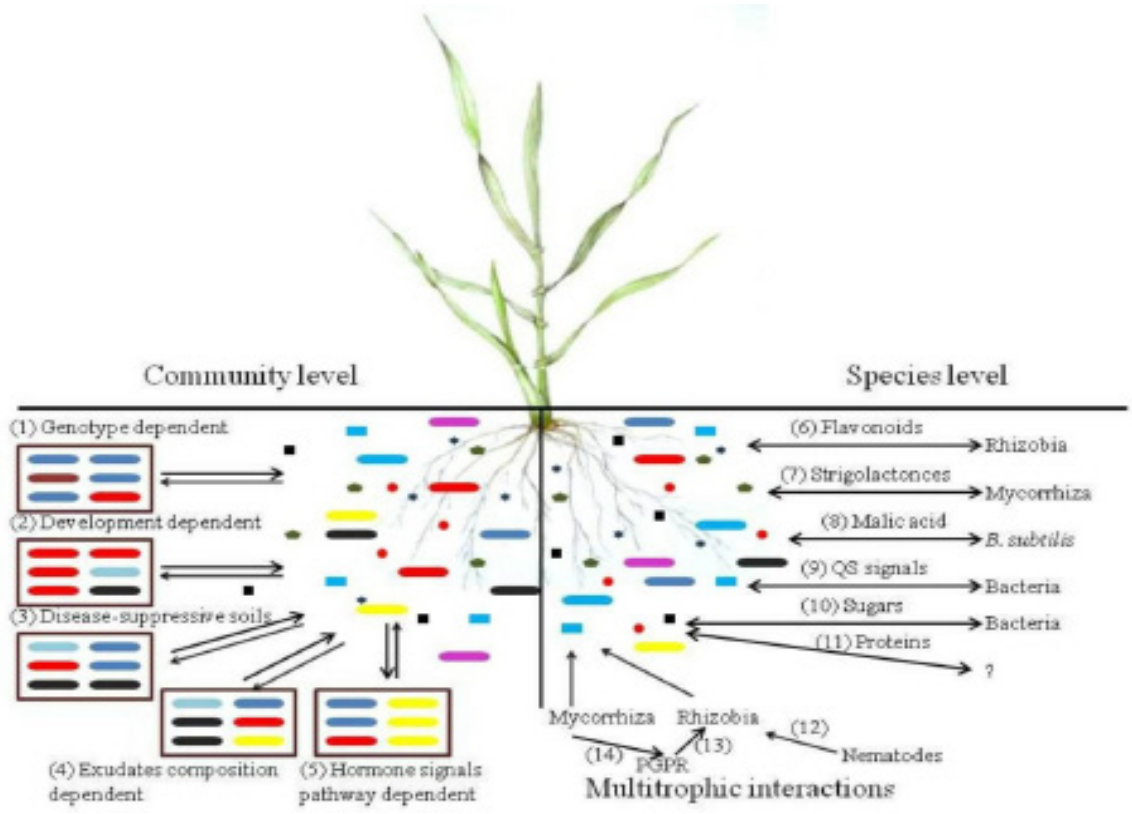

Fig. 2. Plant root exudates mediated rhizospheric interactions: right side-species level, bottom - multitrophic interactions, left side - community level (Huang et al., 2014).

\section{Metagenomics of wheat}

The Wheat being one of the leading cereal crops of the country, has got attention for breeding new lines/ genotypes for higher grain yield, grain quality, resistance against various diseases, and tolerance to abiotic stresses. To a limited extent work has also been carried out to understand the rhizosphere microbiome for enhanced plant growth and grain yield. However, no serious attempt has been made to understand the whole rhizosphere microbiome using the techniques like metagenomics, by which the whole community of microorganisms can be studied and their relationship can be interpreted with plant growth, grain yield or plant's ability to sustain against biotic and abiotic stresses. The work on various aspects of wheat crop like the effect of agronomic practices on rhizosphere microbiome and activation/inactivation of natural nutrient cycling processes, isolation of specific gene/enzyme/protein with ability to biodegrade the lignocellulosic compounds, microbiome of cereal based starters to prepare fermented foods, effect of fungicide application on root microbiome of succeeding wheat crop, variation in levels of microbiome in respect to genotypes and the effect of burning of straw in fields have been compiled along with role of rhizosphere microbiome in exerting the tolerance against abiotic stress in other related crops.

\subsection{Isolation of lignocellulose biodegrading genes from different} sources: In a study carried out to identify the consortia responsible for the degradation of once-used wheat straw, switchgrass and corn stover using molecular fingerprinting, bacterial 16S rRNA gene amplicon sequencing and metagenomic analysis, taxonomically three distinct consortia were found to be involved in degradation of three plant biomasses (Jimenez et al., 2016). In all three microbial consortia, the dominance of gylcosyl hydrolases, a carbohydrate-active enzyme and protein family AA6, AA10 and AA2 were detected. In another study, a novel multispecies microbial consortium responsible for the degradation of lignocellulose and 5-hydroxymethylfurfural bioconversion was identified using the targeted metagenomic approach (Jimenez et al., 2014). Similarly two promising $\beta$-glucosidase were isolated from the topsoil of the winter wheat by using the functional metagenomics (Biver et al., 2014). These enzymes showed activity across a wider $\mathrm{pH}$ (8-10) and temperature range $\left(40-60^{\circ} \mathrm{C}\right)$. While working on the Holstein cattle rumen metagenomic library, Cheng et al., (2012) identified a novel gene fragment containing xylanase. This enzyme was active at $\mathrm{pH}$ of 6.5 and $40{ }^{\circ} \mathrm{C}$, and was specific to xylan from softwood. This enzyme showed the potential to improve biomass degradation and industrial application. Similarly a feruloyl esterase (FAE) gene was 
isolated from rumen microbial metagenome by Wong $e t$ al. (2013). Metagenomic approach has also been utilized for exploring novel tannase from natural communities (Yao et al., 2014).

\subsection{Role in cereal-based fermented foods: An extensive} investigation of the microbiota of cereal-based fermented food by Guyot (2012) has revealed the dominance of lactic acid bacteria. The geno-typing of the isolates has revealed a link between fermented food microbiota and health benefits, especially in nutrition. In a study carried out for microbiome of two traditional wheat based Nuruks, a traditional natural inoculum, used in the brewing of Makgeolli, one of Korea's most popular alcoholic beverages, the two Nuruks revealed a total of 153 and 53 OTUs, respectively. The alpha diversity indices suggest that the two nuruks had different level of diversities and predominated by different species of fungi (Bal et al., 2016).

\subsection{Impact of fungicide application on succeeding wheat crop:}

In a study where a foliar fungicide was applied 5-times to chickpea and its effect was studied on the fungal communities associated with two different types of root systems of the subsequent durum wheat for two years, a three way interaction involving types of roots, year of application, and fungal community composition was recorded. Application of fungicide on chickpea did not show any significant effect on the wheat yields during subsequent years. However, there were changes in root fungal communities (Taheri et al., 2015). The effect of changes in root fungal communities of the wheat on its grain yield has also been discussed in this study. In order to characterize the disease suppressive soils (specific and general suppression), theories have been developed by Schlatter et al. (2017), where in three examples of currentlystudied model systems with features representative of both types of suppressiveness: suppression to take-all (Gaeumannomyces graminis var. tritici), Rhizoctonia bare patch of wheat (Rhizoctonia solani AG-8), and Streptomyces have been discussed. In order to compare the two models of disease suppression, a number of hypotheses about the nature and ecology of microbial populations and communities of suppressive soils have been proposed. The potential and limitations of new molecular techniques that can provide novel ways of testing these hypotheses have also been outlined. Finally, the understanding of the phytobiome and harnessing the potential of indigenous soil microbes for facilitating sustainable disease management in agriculture have been discussed.

\subsection{Different agricultural practices and their impact on rhizosphere} microbiome: Metagenomic studies have been widely used for assessing the role of different agricultural practices, soil organic $\mathrm{C}, \mathrm{N}$-fertilizer, tillage, crop residues, crop rotation or succession and agricultural/crop management on the rhizosphere microbiome of wheat. In order to prove it, a thirteen years long experiment was conducted in Brazil by involving different agricultural practices like conventional tillage, no tillage and crop succession or rotation with wheat, where metagenomics revealed high proportion $(54 \%)$ of bacterial sequences. Tillage was found to influence the microbial diversity to a greater extent compared to other crop management practices. In case of conventional tillage, microbial genera having role in crop residue decomposition, cycling of nitrogen and carbon and involved in breakdown of recalcitrant compounds were significantly higher, predominated by Eucarya reflecting higher tolerance to environmental stresses. Contrary to this $\mathrm{N}$-fixing Rhizobiales and bacteria from Archaea group dominated in no tillage condition. These microorganisms prefer organic matter rich habitats (Souza et al., 2013). In an extended study, where different tillage practices were tried, the same group reported a stable microbial community with higher pesticides degradation capability under no tillage condition. Contrary to this, sequences pertaining to carbohydrate metabolism were higher in conventional tillage practice, a sign of lower organic matter content in the soil. Further, the crop rotation practice exhibited higher sequences pertaining to metabolism of amino acids and their derivatives along with carbohydrate subsystems. It's because of mixing of various types of crop residues in soil in crop rotation practice. The crop rotation also showed a high population of microorganisms without any assigned function (Souza et al., 2015). Similarly in conservation agriculture, Jimenez-Bueno et al. (2016) studied the effect of change in soil environment on prominent bacterial taxa. The rates of $\mathrm{N}$-fertilizer application were recorded to affect mainly the taxa involved in $\mathrm{N}$-cycle, while members of Actinobacteria and microorganisms involved in organic matter decomposition were recorded to be affected by 
tillage. Management of organic matter was found to affect the presence or absence of specific taxa. In order to find out the effect of different agronomic practices on sustainability of a soil, a detailed study was conducted by Chavez-Romero et al. (2016). In this study, the effect of practices like crop residue management, tillage and fertilizer application on bacterial community structure and the microorganisms involved in biodegradation of applied plant residues was studied. The permanent bedsresidue retained treatment exhibited significantly higher levels of soil organic carbon compared with permanent beds-residue burned or conventionally tilled beds-residue incorporated. Converse to this, the permanent beds-residue burned treatment exhibited significantly higher values of $\mathrm{pH}$ and EC compared with soils received fertilizers or no fertilizers in permanent beds-along with residues or conventionally tilled beds-residue incorporated. The bacterial community structure was found to be more affected by organic carbon in soil, application of nitrogen fertilizer and tillage-residue management in unimproved soil compared with improved soil. The tillage-residue management was the key factor in deciding the bacterial community, and it was recorded to induce differences in the genera having role in biodegradation of applied plant residues. Once again it was proved that the practices like application of nitrogen fertilizers and tillage-crop residue management have role in defining the soil bacterial community structure in the unimproved soil compared to improved soil. The study carried out by Rascovan et al. (2016) on rhizosphere microbiomes of soybean and wheat, showed that the beta diversity of rhizospheric microbiome was having relationship with the $\mathrm{pH}$ and nitrate content of the soil. It was also suggested that the plant development and vigor can be promoted by making changing in composition of rhizosphere microbiome. In general, the wheat rhizosphere was found to have the common rhizospheric or bulk soil bacteria, and Pseudomonas, Stenoprophomonas and Bacillus were the most abundant (Velázquez-Sepúlveda et al., 2012).

2.5 Microbiomes specific to wheat cultivars: In order to explore the proposition that the variation in genotypes affect the distribution of rhizospheric microbial phyla, a study was conducted by Naz et al. (2014), by involving two wheat cultivars and the rhizospheric bacterial diversity was studied at the flowering stage using 16S rRNA rhizosphere libraries. The study reported a difference of 13, 50, 36, $78,91 \%$ at phylum, class, order, family and genera level, respectively between two cultivars. Beneficial bacteria with potential to affect plants and soil health were recorded from both cultivars. In order to develop Brachypodium distachyon as the model plant for monocotyledons especially cereals like wheat, a detailed study was conducted to characterize the rhizosphere microbiome and root exudates of this plant (Kawasaki et al., 2016). The rhizosphere microbiota and root exudates of Brachypodium distachyon were similar to that of wheat, and were different to Arabidopsis. During the investigation of the functional genes categories in the microorganisms' isolated from different regions of the root, the microorganisms from around root tips were different from microorganisms from bases of roots.

\subsection{Rice straw burning and effect on soil microbiome: Two} methods of rice straw burning (dispersive and intensive) were investigated for their effect on soil temperature and survivability of microorganisms. Both methods were recorded to enhance the soil temperature. However, it was higher with intensive method compared with dispersive method. Consequently, the effect on microorganisms was also higher by the intensive method compared with dispersive method. The recovery of microorganisms was superior from soil on which intensive burning was performed compared to soil with dispersive burning (Tung et al., 2014).

\section{Microbiome for supporting plant growth under abiotic stress}

Abiotic stresses are the unfavourable growth conditions created by the non-living components of the environment. The response of the plant depends upon the type and the extremity of the stress. The stress can be related to the low or high temperature, drought, water logging, salt level, soil or air pollutants or the hazardous compounds like heavy metals in the soil or water. Among different mechanisms exercised by the plants for their survival under abiotic stress conditions, the role of rhizospheric microbiome is also in vogue. It has also been hypothesized that the survival of some plants species under extreme stress conditions is influenced by rhizosphere microbiome (Jorquera et al., 2012). In a study by Mayak et al. (2004 a, b), a soil bacterial isolate Achromobacter piechaudii ARV8, 
Table 1. Metagenomics work on different aspects of wheat

\begin{tabular}{llll}
\hline Host and location of study & Approach & Main findings & References
\end{tabular}

i) Rhizosphere metagenomics of wheat or related genus

Pre-screening of the resident genetic diversity of wheat rhizosphere (Zamora Michoacan, Mexico; $19^{\circ} 59^{\prime}$ $\mathrm{N}, 102^{\circ} 17^{\prime} \mathrm{W}, 1560$ m.a.s.l.)

PCR amplification, construction of libraries and sequencing of $16 \mathrm{~S}$ rDNA genes
Wheat, oat, pea and an oat mutant (sad1) deficient in production of anti-fungal avenacins (Norwich, UK)

Two cultivars of wheat (Islamabad, Pakistan; $33^{\circ}$ 40' $\mathrm{N}, 73^{\circ} 10^{\prime} \mathrm{E}$ )

Rhizosphere microbiomes of soybean and (Pampas, Argentina)

Brachypodium distachyon, as a rhizosphere model for wheat (Canberra, ACT, Australia; $35^{\circ} 20^{\prime} 17^{\prime \prime} \mathrm{S}$, $149^{\circ} 07^{\prime} 96^{\prime \prime} \mathrm{E}$ )
RNA-based metatranscriptomics

16S rRNA bacterial diversity with RFLP analysis

16S-rRNA gene pyrosequencing

Terminal restriction fragment length polymorphism of $16 \mathrm{~S}$ rRNA and ITS genes of bacteria and fungi, respectively
Thirty operational taxonomic units, in- Velázquezcluding the Classes Alfaproteobacteria, Sepúlveda et al. Betaproteobacteria, Deltaproteobacteria, (2012) Gammaproteobateria, Actinobacteria, Bacilli, Clostridia and uncultivable bacteria were reported. In general the wheat rhizosphere was found to have the common rhizospheric or bulk soil bacteria and Pseudomonas, Stenoprophomonas and Bacillus were the most abundant.

Differences were reported in rhizosphere microbiomes of different plant species and from bulk soil. Considerable differences were noted in the rhizospheremicrobiome of pea, compared to wheat and oat.

The rhizosphere microbiome of two culti- Naz et al. (2014) vars exhibited microbial communities representing 8 phyla, 14 classes, 14 orders, 23 families, 33 genera in addition to several unspecified and un-characterized lineages with good possibility of novel lineages. The two cultivars exhibited a difference of $13,50,36,78,91 \%$ at phylum, class, order, family and genera level, respectively.

The $\mathrm{pH}$ and nitrate content of the soil were found to affect the distribution of regional vs local diversity of the bacterial communities present in rhizosphere. It was also suggested that the growth and quality of plants can be promoted by making changes in the root microbiome.

Rascovan et al.

Burkholderiales were recorded to dominate in Kawasaki et al. rhizospheremicrobiota of Brachypodium. Varia- (2016) tion in composition of microbes was recorded because of their location on roots, like tightly or loosely bound to roots, present on nodal or seminal roots and location along the roots. The functional genes categories recorded in microorganisms present on bases of roots were different than on around root tips. The rhizospheric microbiome and the root exudates recorded in Brachypodium were matching with those of wheat instead of Arabidopsis.
(2016)

Turner et al. (2013) 
ii) Lignocellulosic biomass converting enzymes

Consortia responsible for the degradation of onceused wheat straw, switch grass and corn stover (Groningen, The Netherlands; $53^{\circ} 41^{\prime}$ $\mathrm{N} ; 6^{\circ} 90^{\prime} \mathrm{E}$ )

Microbial consortia responsible for the degradation of lignocellulose and 5-hydroxymethylfurfural bioconversion using carbon and energy from wheat straw (Groningen, The Netherlands)

$\beta$-glucosidase from the topsoil of the winter wheat (Gembloux, Belgium; 50 ${ }^{\circ}$ $33^{\prime} \mathrm{N}, 4^{\circ} 42^{\prime} \mathrm{E}$ )
Molecular fingerprinting, bacterial $16 \mathrm{~S}$ rRNA gene amplicon sequencing and metagenomic analyses

Targeted metagenomic approach (log 16S rRNA and ITS1 copies/ $\mathrm{ml}$ )

Functional metagenomics

Two promising $\beta$-glucosidase were isolated from the topsoil of the winter wheat. These enzymes showed activity across a wider $\mathrm{pH}$ (8-10) and temperature range $\left(40-60{ }^{\circ} \mathrm{C}\right)$.
Jimenez et al.

(2016)

found to be involved in degradation of three plant biomasses. In all three microbial consortia, the dominance of gylcosyl hydrolases - a carbohydrate-active enzyme and protein family AA6, AA10 and AA2 were detected.

A novel multispecies microbial consor- Jimenez et al. tium responsible for the degradation of lig- (2014) nocellulose and 5-hydroxymethylfurfural bioconversion was identified, with hemicellulolytic and oxidoreductase activities.

iii) Cereal based starter/fermented foods

Cereal-based fermented food (Montpellier, Cedex 05 , France)

Two traditional wheat based Nuruks, a very popular natural starter, used in Korea for brewing of Makgeolli- a popular alcoholic beverages (Jeollabuk-do, Republic of Korea)
Genotyping of isolates and 'omic' approach

ITS 1 ampliconpyrosequencing

(n)

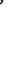

(1)


v) Effect of agronomic practices on rhizospheremicrobiome

Effect of different agricul-
tural practices, soil organic
$\mathrm{C}, \mathrm{N}$-fertilizer, tillage, crop
residues, crop rotation or
succession and agricultural/
crop management on the
rhizosphere microbiome
of wheat(Londrina, State
of Paraná, Brazil; $23^{\circ} 11^{\prime} \mathrm{S}$,
$51^{\circ} 11^{\prime} \mathrm{W}, 620$ m.a.s.l.)

Comparison of soil types and crop management practices in a long term field experiment (Londrina, State of Paraná, Brazil; $23^{\circ} 11^{\prime} \mathrm{S}$, $51^{\circ} 11^{\prime} \mathrm{W}, 620$ m.a.s.l.)

Effect of change of soil environment (conventional or conservation agriculture) on key bacterial taxa of wheat and maize (CIMMYT) Norman E. Borlaug (CENEB) Ciudad Obregon, Sonora, Mexico; $27^{\circ} 22^{\prime} 10^{\prime \prime} \mathrm{N}, 109^{\circ}$ $55^{\prime} 51^{\prime \prime} \mathrm{E}, 38$ m.a.s.l)

Effect of crop residue management, tillage and fertilizer application practices on bacterial community structure and microbial groups with their role in wheat and maize residues biodegradation (Sonora, Mexico; $27^{\circ} 33^{-} \mathrm{N}, 109^{\circ} 09^{-}$ W, 38 m.a.s.l.)

\author{
Shotgun \\ sequencing ap- \\ proach
}

Shotgun

sequencing ap-

proach
Tillage or no tillage was found to have more pronounced effect compared to other crop management practices. The conventional tillage practice was found to support the growth of microorganisms involved in decomposition of crop residues, carbon and nitrogen utilization and breakdown of recalcitrant compound. Contrary to this no-tillage practice was found to support the growth of microorganisms like N-fixing Rhizobiales and Archaea, habitual of growing in organic carbon rich environment

The microbial community was stable under no-tillage condition and it also supported higher degradation of pesticides. The conventional tillage was predominated by sequences pertaining to carbohydrate utilization, a reflection of low organic matter content. The practice of crop rotation was recorded to exhibit higher sequences pertaining to amino acids and their derivatives utilization as well as carbohydrate sub-system. It was attributed to variety of crop residues added in soil. It also exhibited high numbers of microorganisms without any specific function.
16S-rRNA gene metagenomanalysis

16S-rRNA gene pyrosequencing ics, and IndVal

$\mathrm{N}$-fertilizer application rates were recorded to Jimenez-Bueno affect the taxa involved in nitrogen cycling, et al. (2016) while tillage in members of Actinobacteria and microorganisms having role in organic matter decomposition. Organic matter was recorded to affect the taxa more than any other factor.

Souza et al. (2015)

(2013)

The unimproved soil showed significant efChavez-Romefect of soil organic carbon, applied nitrogen ro et al. (2016) and tillage-residue management on the bacterial community composition compared to improved soil. The tillage-residue management was found to be the critical factor in determining the bacterial genera with their role in applied plant material degradation. The effect of nitrogen fertilization and tillage-crop residue management on soil bacterial composition was more clear in unimproved soil than in improved soil. 
isolated from an arid and saline environment has been reported to significantly increase the growth of tomato and pepper seedlings put to transient drought stress. Similarly, the rhizobacteria have been reported to support the growth of plants under flooding condition (Grichkoand Glick, 2001). Soil salinity is another abiotic stress, which affects the plant growth by inducing osmotic and drought stresses. Under salinity conditions, the halotolerant bacteria grow in the company of the host plant and modulate the traits in a fashion, which help the plant to grow. In one such report on wheat grown under saline condition, 24 rhizobacterial isolates out of 130, were found to be tolerant against high levels of sodium chloride (Upadhyay et al., 2009). The entire 24 isolates were found to produce indole-3-acetic acid, while 10 isolates were phosphorus solubilizer, 8 siderophores producer, 6 gibberellin producer, and 2 with the nif $\mathrm{H}$ gene, indicating their nitrogen fixation potential. Bacillus predominated among the bacterial genus isolated from the saline conditions (Upadhyay et al., 2009). Halotolerant bacteria have also been reported from the Korea's coastal soils and several of them have been reported to support the plant growth under saline stress conditions (Siddikee et al., 2010). In a study, Jha et al. (2012) have reported several new halotolerant diazotrophic bacteria (Brachybacterium saurashtrense sp. nov., Zhihengliuella sp., Brevibacterium casei, Haererehalobacter sp., Halomonas sp., Vibrio sp., Cronobacter sakazakii, Pseudomonas spp., Rhizobium radiobacter and Mesorhizobium sp.) from the rhizosphere of Salicornia brachiate, a extreme halophyte. These bacteria were also recorded to have activities like indole acetic acid production, phosphate solubilization, and 1-aminocyclopropane-1-carboxylic acid (ACC) deaminase. Research workers have suggested several possible mechanisms for altering rhizospheric microorganisms mediated plant physiological response under saline stress conditions. It includes; (i) osmolyte accumulation induced water homeostasis, (2) plant energetics by modulating the source-sink relationships, (3) uptake of toxic ions and nutrients mediated through alteration of host physiology, modification of physical barriers around the roots, or by directly reducing the foliar accumulation of toxic ions, and (4) change in crop salt tolerance mediated through hormonal root-shoot signaling (Dodd and Perez-Alfocea, 2012; Berg et al., 2013). Low temperature is another environmental stress condition, which favours microorganisms habituated of growing under psychrotrophic conditions. Normally nodule formation and nitrogen fixation is not favoured by low temperature. However, in one such study, the legumes belonging to the high arctic region have been found to form nodules and fix nitrogen almost at same level as is being done by legumes in temperate climates (Bordeleau and Prevost, 1994). The information on use of microbial inoculants for promoting the growth of horticultural and agricultural crops under cold conditions is quite scanty. Still in one report, Burkholderia phytofirmans PsJNhas been reported to increase the growth of roots as well as physiological activity of grapevine at temperatures as low as $4^{\circ} \mathrm{C}$ (Barka et al., 2006). Similarly, the coinoculation of Bradyrhizobium japonicum with Serratia proteamaculans at $15^{\circ} \mathrm{C}$, sub-optimal temperature for soybean nodule infection and nitrogen fixation, has been recorded to promote the growth of soybean (Zhang et al., 1995; 1996). Attempts have also been made to find out the mechanisms responsible for promotion of plant growth at low temperature conditions (Katiyar and Goel, 2003; Trivedi and Sa, 2008). In both cases, the cold tolerant mutants of Pseudomonas fluorescens and P. corrugata strains exhibited higher phosphorus solubilization at low temperature compared to their wild type strains. The genes responsible for cold tolerance and phosphorus solubilization have not been worked out in both cases. Unfavourable $\mathrm{pH}$ of soil or irrigation water and high concentration of toxic compounds are the few other abiotic factors that also affect plant growth. In one such study, a 2,4 diacetylphloroglucinol (DAPG)-producing $P$. fluorescens strain has been reported to minimize the effect of low $\mathrm{pH}$ in corn plants grown under low $\mathrm{pH}$ conditions (Raudales et al., 2009). Rhizoremediationis the term much in vogue recently and it is the process of bioremediating soil pollutants by rhizospheric bacteria. During this process, the plants' root exudates promote the growth and activity of pollutant degrading rhizobacteria (Kuiper et al., 2004). The use of some metagenomic techniques including $16 \mathrm{~S}$ rRNA gene pyrosequencing, have shown that certain legumes including Trifolium respond in a systemic manner to polycyclic aromatic hydrocarbons pollution (Kawasaki et al., 2012). The shift in predominance of certain groups of bacteria (Verrucomicrobia and Actinobacteria) in the polluted rhizospheres, and substantial increase in the numbers of betaproteobacterium Denitratisoma, suggest that these groups or genus may have role in the rhizoremediation process (Kawasaki et al., 2012). In few cases, the role of fungi has also been reported in 
rhizoremediation of hydrocarbons (Cruz-Hernandez et al., 2012). The research carried out till date by various research groups under different abiotic and biotic stress situations have proved the worthiness of rhizosphere microbiome in alleviating the adverse effects of abiotic and biotic stresses on plant growth. It has the ability to provide an alternative to genetic engineering and plant breeding. However, there are certain questions which need to be answered.

i) Communication mechanism between plant growth promoting rhizobacteria and the host plant

ii) Types of changes induced in plants; molecular as well as metabolic,

iii) Mechanism of affecting the changes in overall population and disease causing ability of plant pathogenic microorganisms by the beneficial microorganisms.

\section{Plant breeding and genetic engineering approaches for modulating rhizosphere microbiome}

The role of root exudates in regulation of varied types of interactions between rhizosphere microbiome and the plant viz., attraction of disease causing microorganisms or the beneficial microorganisms and activation of plant virulence factor in presence of pathogenic microorganisms or the plant growth functions in presence of plant growth promoting rhizobacteria, modulating the levels or the composition of root exudates using conventional plant improvement techniques or genetic engineering can be a viable strategy for modulating the rhizosphere microbiome. The approach of redirecting the composition and the quality of the rhizospheric microbiome is known as 'rhizosphere engineering' (Oger et al., 2004; Ryan et al., 2009; Bakker et al., 2012), as it necessitates the thorough knowledge of the complete spectrum of root exudates and the signaling happening at molecular level in the plant root environment involving the rhizosphere microbiome and the host plant. The breeding programs involving rhizosphere related traits and root exudates characterization as part of their breeding programme are rare and very few in numbers (Smith and Goodman, 1999; Smith et al., 1999; Rengel, 2002; Wissuwa et al., 2009) and no program has been reported that evaluate new genotypes for their interactive behavior with rhizosphere microbiome (Bakker et al., 2012).

In an initial study, attempt has been made to find out the genetic basis of interaction with rhizosphere bacteria having role in restricting plant pathogens growth (Smith et al., 1999). During the course of investigation in several breeding lines of tomato, three QTLs have been recognized and further attempt has been made to find out the loci linked to resistance against Pythium torulosum, role of Bacillus cereus in disease suppression and its growth on the seeds. These QTLs were also found helpful in elucidation of the dissimilarity among the recombinant breeding lines to the extent of $38 \%$. The study further proved that the genetic variation of the host plant can be used for enhancing the favorable association between plants and the rhizosphere microbiome. Few genetic engineering attempts have also been made to change the $\mathrm{pH}$ of the root zone (Gevaudant et al., 2007; Yang et al., 2007), outflow of organic anion (Tesfaye et al., 2001; Anoop et al., 2003; Delhaize et al., 2004; Sasaki et al., 2004; Li et al., 2005), or easy outflow of citrate (Furukawa et al., 2007; Wang et al., 2007). There are also several other reports where the plants have been reported to excrete out chemicals with their role in sensing bacterial quorum (Gao et al., 2003; Bauer and Mathesius, 2004). In a study, the genetically modified potato interfering in sensing of bacterial quorum through expression of a lactonase gene, has been reported to show a superior level of resistance against Pectobacterium carotovorum (Dong et al., 2001). Similarly the transgenic potato with enhanced production level of 5-O-glucosyltransferase (Lorenc-Kukula et al., 2005) and pectatelyase (Wegener, 2001) also exhibited enhanced resistance against $P$. carotovorum. Presently, our understanding on in situ root exudation is quite limited, and root exudation varies across environments, soil types, and the growth stage/physiological conditions of the plant.

\section{Conclusion and future prospects}

Plant microbiome regulates and influences the physiology and development of the plant. It contributes in nutrient acquisition from soil, tolerance against stresses, resistance against soil born pathogens and modulation of plant immune system. Using routine cultural techniques, it is possible to culture only very limited numbers of microorganisms and studying them for beneficial traits. However, the techniques like metagenomics are very handy in studying the whole community in action, interaction between different components of the community and the metabolic pathways/genes active under a particular environmental condition. The application of this technique becomes more relevant under stress conditions because 
abiotic stresses affect the plant growth via root system as the root system interacts both the above ground and below ground environments simultaneously. Through this review attempt has been made to compile the information available on metagenomics study of wheat and to find out its utility in developing climate resilient genotypes. In the time to come the genotype specific microbiome will be available and it will be used as biomarker for developing climate resilient varieties. The consortia of beneficial microorganisms will also come in picture for helping the plants to survive under stress conditions or it will be used to induce plant to excrete out specific set of roots exudates providing survival advantage under stress conditions.

\section{References}

1. Alexander M. 1977. Introduction to Soil Microbiology, 2nd edn. John Wiley \& Sons, New York. 467 PP.

2. Anoop VM, U Basu, MT McCammon, HL McAlister and GJ Taylor. 2003. Modulation of citrate metabolism alters aluminum tolerance in yeast and transgenic canola overexpressing a mitochondrial citrate synthase. Plant Physiology 132: 2205-2217.

3. Bakker MG, DK Manter, AM Sheflin, TL Weir and JM Vivanco. 2012. Harnessing the rhizosphere microbiome through plant breeding and agricultural management. Plant and Soil 360: 1-13.

4. Bakker PAHM, RL Berendsen, RF Doombos, PCA Wintermans and CML Pieterse. 2013. The rhizosphere revisited: root microbiomics. Frontiers in Plant Science 4:165-171.

5. Bal J, SH Yun, SH Yeo, JM Kim and DH Kim. 2016. Metagenomic analysis of fungal diversity in Korean traditional wheat based fermentation starter nuruk. Food Microbiology 60: 73-83.

6. Barka EA, J Nowak and C Clement. 2006. Enhancement of chilling resistance of inoculated grapevine plantlets with a plant growth-promoting rhizobacterium, Burkholderia phytofirmans strain PsJN. Applied and Environmental Microbiology 72: 7246-7252.

7. Bauer WD and U Mathesius. 2004. Plant responses to bacterial quorum sensing signals. Current Opinion in Plant Biology 7: 429-433.

8. Beckers B, MOD Beeck, N Weyens, W Boerjan and J Vangronsveld. 2017. Structural variability and niche differentiation in the rhizosphere and endosphere bacterial microbiome of field-grown poplar trees. Microbiome 5: 25-41. DOI 10.1186/s40168-017-0241-2

9. Berendsen RL, CMJ Pieterse and P Bakker. 2012. The rhizosphere microbiome and plant health. Trends in Plant Science 17: 478-486.

10. Berg G, MAlavi, CSchmidt, CZachow,D Egamberdieva, B Kamilova and BJJ Lugtenberg. 2013. Biocontrol and osmoprotection for plants under salinated conditions. In: Molecular Microbial Ecology of the Rhizosphere (Eds. FJ de Bruijn), John Wiley \& Sons, Inc., Hoboken, NJ. pp. 587-592.

11. Berg G, M Grube, M Schloter and K Smalla. 2014. Unraveling the plant microbiome: looking back and future perspectives. Frontiers in Microbiology 5:148-154. doi: 10.3389/fmicb.2014.00148. eCollection 2014.

12. Biver S, A Stroobants, D Portetelle and M Vandenbol. 2014. Two promising alkaline $\beta$ glucosidases isolated by functional metagenomics from agricultural soil, including one showing high tolerance towards harsh detergents, oxidants and glucose. Journal of Industrial Microbiology and Biotechnology 41:479-488.

13. Bordeleau L and D Prevost. 1994. Nodulation and nitrogen fixation in extreme environments. Plant and Soil 161: 115-125.

14. Brady NC. 1974. The Nature and Properties of Soils, 9th edn. Macmillan, New York. 750 PP

15. Buee M, W De Boer, F Martin, L van Overbeek and EJurkevitch. 2009. The rhizosphere zoo: an overview of plant-associated communities of microorganisms, including phages, bacteria, archaea, and fungi, and of some of their structuring factors. Plant and Soil 321: 189-212.

16. Chávez-Romeroa Y, YE Navarro-Noyab, SC ReynosoMartíneza, Y Sarria-Guzmána, B Govaertsc, N Verhulstc, L Dendoovena and M Luna-Guidoa. 2016. $16 \mathrm{~S}$ metagenomics reveals changes in the soil bacterial community driven by soil organic $\mathrm{C}, \mathrm{N}$-fertilizer and tillage-crop residue management. Soil and Tillage Research 159: 1-8.

17. Cheng F, J Sheng, R Dong, Y Men, L Gan and L Shen. 2012. Novel Xylanase from a Holstein Cattle Rumen Metagenomic Library and Its Application in Xylooligosaccharide and Ferulic Acid Production from Wheat Straw. Journal of Agricultural and Food Chemistry 60: 12516-12524. 
18. Cook RJ, LS Thomashow, DM Weller, D Fujimoto, M Mazzola, G Bangera and DS Kim. 1995. Molecular mechanisms of defense by rhizobacteria against root disease. Proceedings of the National Academy of Sciences of the United States of America 92: 4197-4201.

19. Cruz-Hernandez A, A Tomasini-Campocosio, L Perez-Flores, F Fernandez-Perrino and MGutierrezRojas. 2012. Inoculation of seed-borne fungus in the rhizosphere of Festuca arundinacea promotes hydrocarbon removal and pyrene accumulation in roots. Plant and Soil 363: 261-270.

20. Delhaize E, PR Ryan, DM Hebb, Y Yamamoto, T Sasaki and H Matsumoto. 2004. Engineering high-level aluminum tolerance in barley with the ALMT1 gene. Proceedings of the National Academy of Sciences of the United States of America 101: 15249-15254.

21. Dennis PG, AJ Miller and PR Hirsch. 2010. Are root exudates more important than other sources of rhizodeposits in structuring rhizosphere bacterial communities? FEMS Microbiology Ecology 72: 313-327.

22. Dodd IC and F Perez-Alfocea. 2012. Microbial amelioration of crop salinity stress. Joumal of Experimental Botany 63: 3415-3428.

23. Dong YH, LH Wang, JL Xu, HB Zhang, XF Zhang and LH Zhang. 2001. Quenching quorumsensing-dependent bacterial infection by an $\mathrm{N}$-acyl homoserinelactonase. Nature 411: 813-817.

24. Furukawa J, N Yamaji, H Wang, N Mitani, Y Murata, K Sato, M Katsuhara, K Takeda and JF Ma. 2007. An aluminum-activated citrate transporter in barley. Plant and Cell Physiology 48: 1081-1091.

25. Gao MS, M Teplitski, JB Robinson and WD Bauer. 2003. Production of substances by Medicago truncatula that affect bacterial quorum sensing. Molecular PlantMicrobe Interactions 16: 827-834.

26. Gevaudant F, G Duby, E von Stedingk, R Zhao, P Morsomme and M Boutry. 2007. Expression of a constitutively activated plasma membrane $\mathrm{H}+$-ATPase alters plant development and increases salt tolerance. Plant Physiology 144: 1763-1776.

27. Grichko VP and BR Glick. 2001. Amelioration of flooding stress by ACC deaminase containing plant growth-promoting bacteria. Plant Physiology and Biochemistry 39: 11-17.

28. Guyot JP. 2012. Cereal-based fermented foods in developing countries: ancient foods for modern research. International Journal of Food Science and Technology 47: 1109-1114.

29. Hartmann A, M Schmid, D van Tuinen and G Berg. 2009. Plant-driven selection of microbes. Plant and Soil 321: 235-257.

30. Huang XF, JM Chaparro, KF Reardon, R Zhang, Q Shen and JM Vivanco. 2014. Rhizosphere interactions: root exudates, microbes, and microbial communities. Botany 92: 267-275. doi.org/10.1139/cjb-2013-0225

31. Jha B, I Gontia and A Hartmann. 2012. The roots of the halophyte Salicornia brachiata are a source of new halotolerant diazotrophic bacteria with plant growthpromoting potential. Plant and Soil 356: 265-277.

32. Jiménez DJ, MJ de Lima Brossi, J Schückel, SK Kračun, W George, T Willats and JD van Elsas. 2016. Characterization of three plant biomassdegrading microbial consortia by metagenomics and metasecretomics based approaches. Applied Microbiology and Biotechnology 100:10463-10477.

33. Jiménez DJ, E KorenblumandJD van Elsas. 2014a. Novel multispecies microbial consortia involved in lignocellulose and 5-hydroxymethylfurfural bioconversion. Applied Microbiology and Biotechnology 98:2789-2803.

34. Jimenez-Bueno NG, C Valenzuela-Encinas, R Marsch, D Ortiz-Gutierrez, N Verhulst, B Govaerts, L Dendooven and YE Navarro-Noya. 2016. Bacterial indicator taxa in soils under different long-term agricultural management. Journal of Applied Microbiology 120: 921-933.

35. Jones DL, C Nguyen and RD Finlay. 2009. Carbon flow in the rhizosphere: carbon trading at the soil-root interface. Plant and Soil 321:5-33.

36. Jorquera MA, B Shaharoona, SM Nadeem, M de la Luz Mora and DE Crowley. 2012. Plant growth-promoting rhizobacteria associated with ancient clones of creosote bush (Larreatridentata). Microbial Ecology 64: 1008-1017.

37. Katiyar V and R Goel. 2003. Solubilization of inorganic phosphate and plant growth promotion by cold tolerant mutants of Pseudomonas fluorescens. Microbiological Research 158: 163-168.

38. Kawasaki A, S Donn, PR Ryan, U Mathesius, R Devilla, A Jones and M Watt. 2016. Microbiome and Exudates of the Root and Rhizosphere of Brachypodium distachyon, a Model for Wheat. PLoS ONE 11(10): 1-25 e0164533. doi:10.1371/journal.pone.0164533. 
39. Kawasaki A, ER Watson and MA Kertesz. 2012. Indirect effects of polycyclic aromatic hydrocarbon contamination on microbial communities in legume and grass rhizospheres. Plant and Soil 358: 169-182.

40. Kuiper I, EL Lagendijk, GV Bloemberg and BJJ Lugtenberg. 2004. Rhizoremediation: a beneficial plant-microbe interaction. Molecular Plant-Microbe Interactions 17: 6-15.

41. Lakshmanan V, SL Kitto, JL Caplan, YH Hsueh, DB Kearns, YS Wu and HP Bais. 2012. Microbe-associated molecular patterns triggered root responses mediate beneficial rhizobacterial recruitment in Arabidopsis. Plant Physiology 160(3):1642-1661.

42. Lakshmanan V, G Selvaraj, HP Bais. 2014. Functional soil microbiome: belowground solutions to an aboveground problem. Plant Physiology 166(2):689-700.

43. Li JY, RK Xu, SC Xiao and GL Ji. 2005. Effect of low-molecular-weight organic anions on exchangeable aluminum capacity of variable charge soils. Journal of Colloid and Interface Science 284: 393-399.

44. Lorenc-Kukula K, S Jafra, J Oszmianski and J Szopa. 2005. Ectopic expression of anthocyanin 5-O-glucosyltransferase in potato tuber causes increased resistance to bacteria. Journal of Agricultural and Food Chemistry 53: 272-281.

45. Lynch JM (1988) The terrestrial environment. In: Microorganisms in Action: Concepts and Applications in Microbial Ecology (Eds. JM Lynch and JEHobbie), Blackwell Scientific, Oxford. pp. 75-100.

46. Mayak S, T Tiroshand BR Glick. 2004a. Plant growthpromoting bacteria that confer resistance to water stress in tomatoes and peppers. Plant Science 166: 525-530.

47. Mayak S, T Tirosh and BR Glick. 2004b. Plant growthpromoting bacteria confer resistance in tomato plants to salt stress. Plant Physiology and Biochemistry 42: 565-572.

48. Meeting FB (1992) Soil Microbial Ecology: Applications in Agricultural and Environmental Management. Marcel Dekker, New York.

49. Mendes R, P Garbeva and JM Raaijmakers. 2013. The rhizosphere microbiome: significance of plant beneficial, plant pathogenic and human pathogenic microorganisms. FEMS Microbiology Review 37: 634-663.

50. Mendes R, M Kruijt, I de Bruijn, E Dekkers, M van der Voort, JH Schneider, YM Piceno, TZ DeSantis, GL Andersen, PA Bakker and JM Raaijmakers. 2011.
Deciphering the rhizosphere microbiome for diseasesuppressive bacteria. Science 332: 1097-1100.

51. Naz I, RS Mirza and ABano. 2014. Molecular characterization of rhizosphere bacterial communities associated with wheat (Triticum aestivuml) cultivars at flowering stage. Journal of Animal and Plant Sciences 24(4): 1123-1134.

52. Nelson EB. 2004. Microbial dynamics and interactions in the spermosphere. Annual Review of Phytopathology 42: 271-309.

53. Oger P, H Mansouri and Y Dessaux. 2000. Effect of crop rotation and soil cover on alteration of the soil microflora generated by the culture of transgenic plants producing opines. Molecular Ecology 9: 881-890.

54. Oger P, A Petit andY Dessaux. 1997. Genetically engineered plants producing opines alter their biological environment. Nature Biotechnology 15: 369-372.

55. Oger PM, H Mansouri, X Nesme andY Dessaux. 2004. Engineering root exudation of lotus toward the production of two novel carbon compounds leads to the selection of distinct microbial populations in the rhizosphere. Microbial Ecology 47: 96-103.

56. Perez-Jaramillo JE, R Mendes and JM Raaijmakers. 2016. Impact of plant domestication on rhizosphere microbiome assembly and functions. Plant Molecular Biology 90:635-644.

57. Rascovan N, B Carbonetto, D Perrig, M Díaz, W Canciani, M Abalo, J Alloati, G González-Anta and MP Vazquez. 2016. Integrated analysis of root microbiomes of soybean and wheat from agricultural fields. Scientific Reports 6:28084-28095. doi: 10.1038/srep28084.

58. Raudales RE, E Stone and BB McSpadden Gardener. 2009. Seed treatment with 2,4diacetylphloroglucinolproducing pseudomonads improves crop health in low-pH soils by altering patterns of nutrient uptake. Phytopathology 99: 506-511.

59. Rengel Z. 2002. Breeding for better symbiosis. Plant and Soil245:147-162.

60. Ryan PR, Y Dessaux, LS Thomashow and DM Weller. 2009. Rhizosphere engineering and management for sustainable agriculture. Plant and Soil 321: 363-383.

61. Sasaki T, Y Yamamoto, B Ezaki, M Katsuhara, SJ Ahn, PR Ryan, E Delhaize and HA Matsumoto B. 2004. A wheat gene encoding an aluminum-activated malate transporter. Plant Journal 37: 645-653. 
62. Schlatter D, L Kinkel, L Thomashow, D Weller and T Paulitz. 2017. Disease Suppressive Soils: New Insights from Soil Microbiome. Phytopathology 107: 1284-1297.

63. Siddikee M, P Chauhan, R Anandham, GH Han and T Sa. 2010. Isolation, characterization, and use for plant growth promotion under salt stress, of ACC deaminase-producing halotolerant bacteria derived from coastal soil. Journal of Microbiology and Biotechnology 20: $1577-1584$.

64. Smith KP and RM Goodman. 1999. Host variation for interactions with beneficial plant-associated microbes. Annual Review of Phytopathology 37: 473-491.

65. Smith KP, J Handelsman and RM Goodman. 1999. Genetic basis in plants for interactions with diseasesuppressive bacteria. Proceedings of the National Academy of Sciences of the United States of America 96: 4786-4790.

66. Souza RC, ME Cantão, ATR Vasconcelos, MA Nogueira and M Hungria.2013. Soil metagenomics reveals differences under conventional and no-tillage with crop rotation or succession. Applied Soil Ecology 72: 49-61.

67. Souza RC, M Hungria, ME Cantão, ATR Vasconcelos, MA NogueiraandVA Vicente. 2015. Metagenomic analysis reveals microbial functional redundancies and specificities in a soil under different tillage and cropmanagement regimes. Applied Soil Ecology 86: 106-112.

68. Taheri AE, C Hamel andY Gan. 2015 Pyrosequencing reveals the impact of foliar fungicide application to chickpea on root fungal communities of durum wheat in subsequent year. Fungal Ecology 15: 73-81.

69. Tesfaye M, SJ Temple, DL Allan, CP Vance and DA Samac. 2001. Overexpression of malate dehydrogenase in transgenic alfalfa enhances organic acid synthesis and confers tolerance to aluminum. Plant Physiology 127: 1836-1844.

70. Trivedi $\mathrm{P}$ and $\mathrm{T}$ Sa. 2008. Pseudomonas corrugata (NRRLB-30409) mutants increased phosphate solubilization, organic acid production, and plant growth at lower temperatures. Current Microbiology 56: 140-144.

71. Tung NS, NX Cu and NX Hai. 2014. Impact of rice straw burning methods on soil temperature and microorganism distribution in the paddy soil ecosystems. ARPNJournal of Agricultural Biological Science 9(5): 157-160.

72. Turner TR, EK James and PS Poole. 2013. The plant microbiome. Genome Biology 14:1-10.
73. Upadhyay SK, DP Singh and R Saikia. 2009. Genetic diversity of plant growth promoting rhizobacteria isolated from rhizospheric soil of wheat under saline condition. Current Microbiology 59: 489-496.

74. Velázquez-Sepúlveda I, MC Orozco-Mosqueda, CM Prieto-Barajas and G Santoyo. 2012. Bacterial diversity associated with the rhizosphere of wheat plants (Triticuma estivum): Toward a metagenomic analysis. Phyton-International Journal of Experimental Botany 81: 81-87.

75. Wang J, H Raman, M Zhou, PR Ryan, E Delhaize, DM Hebb, N Coombes and N Mendham. 2007. Highresolution mapping of the Alp locus and identification of a candidate gene HvMATE controlling aluminium tolerance in barley (Hordeumvulgare L.). Theoretical and Applied Genetics 115: 265-276.

76. Wegener CB. 2001. Transgenic potatoes expressing an Erwiniapectatelyase gene - results of a 4-year field experiment. Potato Research 44: 401-410.

77. Wissuwa M, M Mazzola and C Picard. 2009. Novel approaches in plant breeding for rhizosphere-related traits. Plant and Soil 321: 409-430.

78. Wong DWS, VJ Chan, H Liao and MJ Zidwick. 2013. Cloning of a novel feruloyl esterase gene from rumen microbial metagenome and enzyme characterization in synergism with endoxylanases. Journal of Industrial Microbiology and Biotechnology 40: 287-295.

79. Yang H, J Knapp, P Koirala, D Rajagopal, WA Peer, LK Silbart, A Murphy and RA Gaxiola. 2007. Enhanced phosphorus nutrition in monocots and dicots over-expressing a phosphorus-responsive type IH+pyrophosphatase. Plant Biotechnology Journal 5: 735-745.

80. YaoJ, GS Guo, GH Ren and YH Liu.2014. Production, characterization and applications of tannase. Journal of Molecular Catalysis B: Enzymatic 101: 137- 147.

81. Zhang F, N Dashti, R Hynes and DL Smith. 1996. Plant growth promoting rhizobacteria and soybean [Glycine $\max ($ L.) Merr.] nodulation and nitrogen fixation at suboptimal root zone temperatures. Annals of Botany 77: 453-460.

82. Zhang F, DH Lynch and DL Smith. 1995. Impact of low root temperatures in soybean [Glycine $\max$ (L.) Merr.] on nodulation and nitrogen fixation. Environmental and Experimental Botany 35: 279-285. 